\title{
Computer modeling of glued laminated timber beam reinforced with steel bars fixed with epoxy resin
}

\author{
Nina Blokhina ${ }^{1, *}$, and Sergei Nazarenko ${ }^{2}$ \\ ${ }^{1}$ Moscow State University of Civil Engineering, Yaroslavskoye shosse, 26, Moscow, 129337, Russia \\ ${ }^{2}$ Russian University of Transport» (RUT - MIIT), 127994, Moscow, 9b9 Obrazcova Street
}

\begin{abstract}
Structures of glued laminated timber have many technical and economic benefits compared to metal or reinforced concrete: lower weight, sufficient strength and durability. Competent design of such structures requires numerical analysis that best meets specified conditions. This article describes a 3D analysis of a beam composed of glued laminated timber, reinforcement bars and epoxy resin. When determining the stressstrain state of the structure, anisotropic properties of wood were also taken into account. Computer analysis of material behavior of timber, reinforcement bars and epoxy resin was performed with the help of ANSYS software package.
\end{abstract}

\section{Introduction}

Since the earliest history of mankind wood has been a material most widely used in construction all over the world, and it has retained its importance today because of its unique properties that cannot be reproduced artificially. But since extensive use of wood leads to destruction of forests and thus harms the environment, the economy of this valuable material is now a priority with modern construction techniques. A solution of this problem has been found in glued laminated timber, or 'glulam'. Compared to metal or reinforced concrete, glulam exceeds in many ways, including low weight and considerably high rigidity and durability. At the same time its reliability is often undermined by certain disadvantages of wood such as its variable structure, imperfections and tendency to creep under long-term stress. As a structural element beam also has its flaws compared to arch or frame. Tests carried out on plain or glued timber beams along with on-location examination of buildings in a state of disrepair show that transverse forces concentrating mostly at the beam's support points produce high-level tangential stresses that often lead to shear fractures in these areas. One of the methods to overcome these drawbacks and increase economic efficiency of glulam constructions is structural reinforcement: glulam beams are reinforced with steel or fiberglass rebar. This technology enhances the quality and durability of wooden structures, especially those experiencing bending and compression, reduces their weight and generally leads to considerable material savings. In Russia the

\footnotetext{
* Corresponding author: nsb_sapr@mail.ru
} 
method of diagonal and transverse reinforcement was introduced by prof. Turcowski of Central Research Institute of Building and Construction (TSNIISK) and developed by A. Pogoreltsev [1]. Recent research has shown that it helped increase shear durability of glued timber beams by $30-40$ percent. Reinforced glued laminated timber is frequently used in construction of sports facilities, agricultural buildings, warehouses, bridges, chemical plants etc. where its durability is often put to the test by temperature and moisture fluctuations, chemically aggressive environments or alternating load. So today reinforced glulam production needs effective technologies that are still being improved. For example, mechanical joining of rebar and wood has generally been discarded due to low durability, and the joining is performed with the help of synthetic adhesives of which epoxy resin is the most common. As a result, structural analysis of reinforced timber is more complicated compared to other types of reinforced material.

\section{Methods of analysis of glued laminated timber beams}

For many years the analysis of glulam beams was based on simplified models due to low computational powers of computers. Today modern software packages give structural engineers the opportunity to discard theories and carry out a three-dimensional analysis of material behavior of wood, rebar and adhesive working together in life-like conditions.

Modern research in material behavior has supplied the engineers with more data to take into account. For example, S. Lechnitsky, E. Ashkenazi and other authors have shown that the assessment of load bearing capacity of wooden flexural elements must be carried out with regard to anisotropic properties of wood. So the analysis of a reinforced glued laminated timber beam can be regarded as a problem that obviously has no analytical solution and can only be solved by finite element method with the help of a powerful software package. After estimating the potential of several software packages available on the market, the authors have chosen ANSYS package which possesses all the necessary tools to perform a three-dimensional analysis of a structure composed of three materials, one of which is anisotropic [1,2]. This article describes the analysis of a glued laminated timber beam, size $6200 \times 140 \times 600 \mathrm{~mm}$, reinforced with sixteen steel bars. Four bars at the top of the beam and four at the bottom are used as supports. The load equivalent to $100 \mathrm{kH}$ is applied to four bars placed $2000 \mathrm{~mm}$ from the top and bottom edges of the beam. Bar diameter is $20 \mathrm{~mm}$. The bars are fixed with epoxy resin, its layer thickness is $1 \mathrm{~mm}$. The distance between the centers of the bars is $60 \mathrm{~mm}$ across the beam, 150 and 2000 along it.

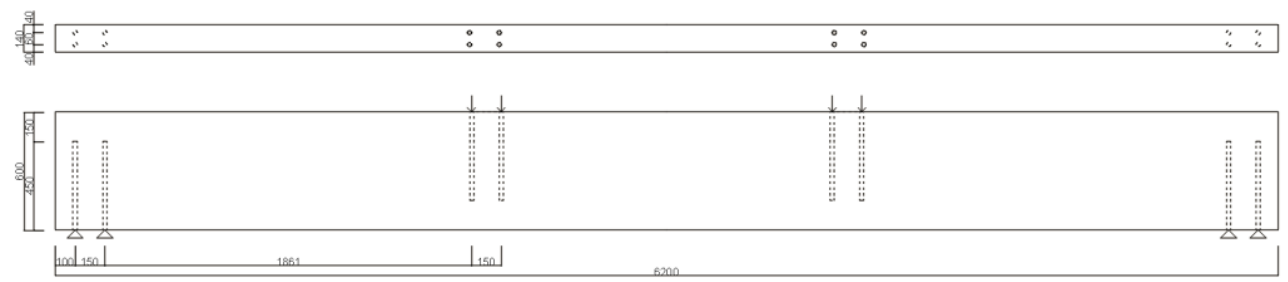

Fig. 1. Calculation model of a reinforced glulam beam.

The authors have performed a 3-dimensional analysis of the beam, rebar and layers of epoxy through the finite element method using ANSYS. One of the advantages of FEM is that granularity can easily be raised in areas of interest. Specifically, in the current task mesh density is increased around reinforcement bars. To create a model of such a complicated structure the authors have used ANSYS macro language. A 1/4th of the model was inserted and then scaled along 2 axes.

A fragment of a macro used for creating the model: 
!defining $1 / 4$ of the picture

rectng, $-3100,0,-70,0 !, 0 !, 600$,

CYL4,-3100+100,-70+40,22, , , ,!450!140 -Z

CYL4,-3100+100,-70+40,20, ,22, , 450

CYL4,-3100+250,-70+40,22, , , , !450

CYL4,-3100+250,-70+40,20, ,22, , !450

CYL4,-3100+2100,-70+40,22, , , , !450

CYL4,-3100+2100,-70+40,20, ,22, ,!450

CYL4,-3100+2250,-70+40,22, , , ,!450

CYL4,-3100+2250,-70+40,20, ,22, ,!450

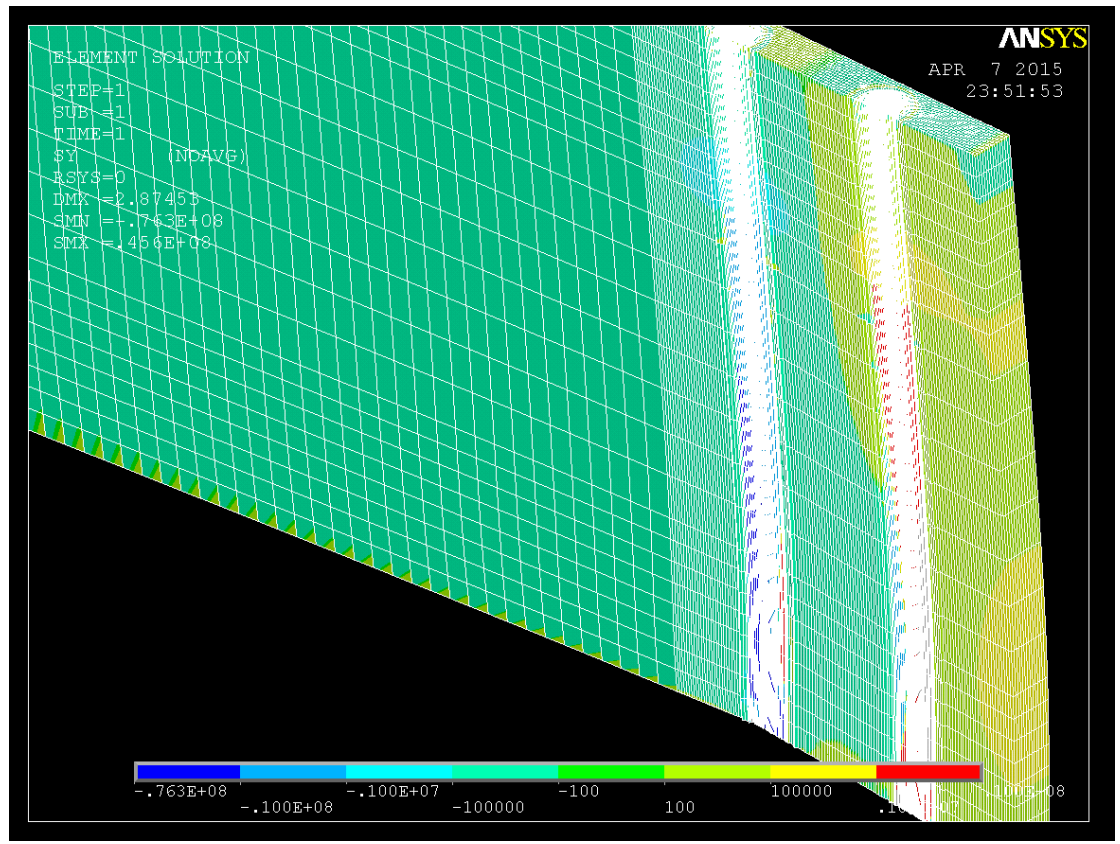

Fig. 2. Contour plots of vertical stresses in timber in areas close to support bars.

Steel reinforcement enhances stability of the whole structure by means of distributing bearing reaction forces along the beam, which prevents local working stresses across the grain. The use of glued-in rebars also excludes close contact between timber and concrete or brick support, providing gaps for ventilation. One of the most valuable advantages of steel reinforcement is that timber beams can now be joined by welding, making the whole structure more reliable. Steel bars inside the beam are also well protected from corrosion in aggressive environment. 


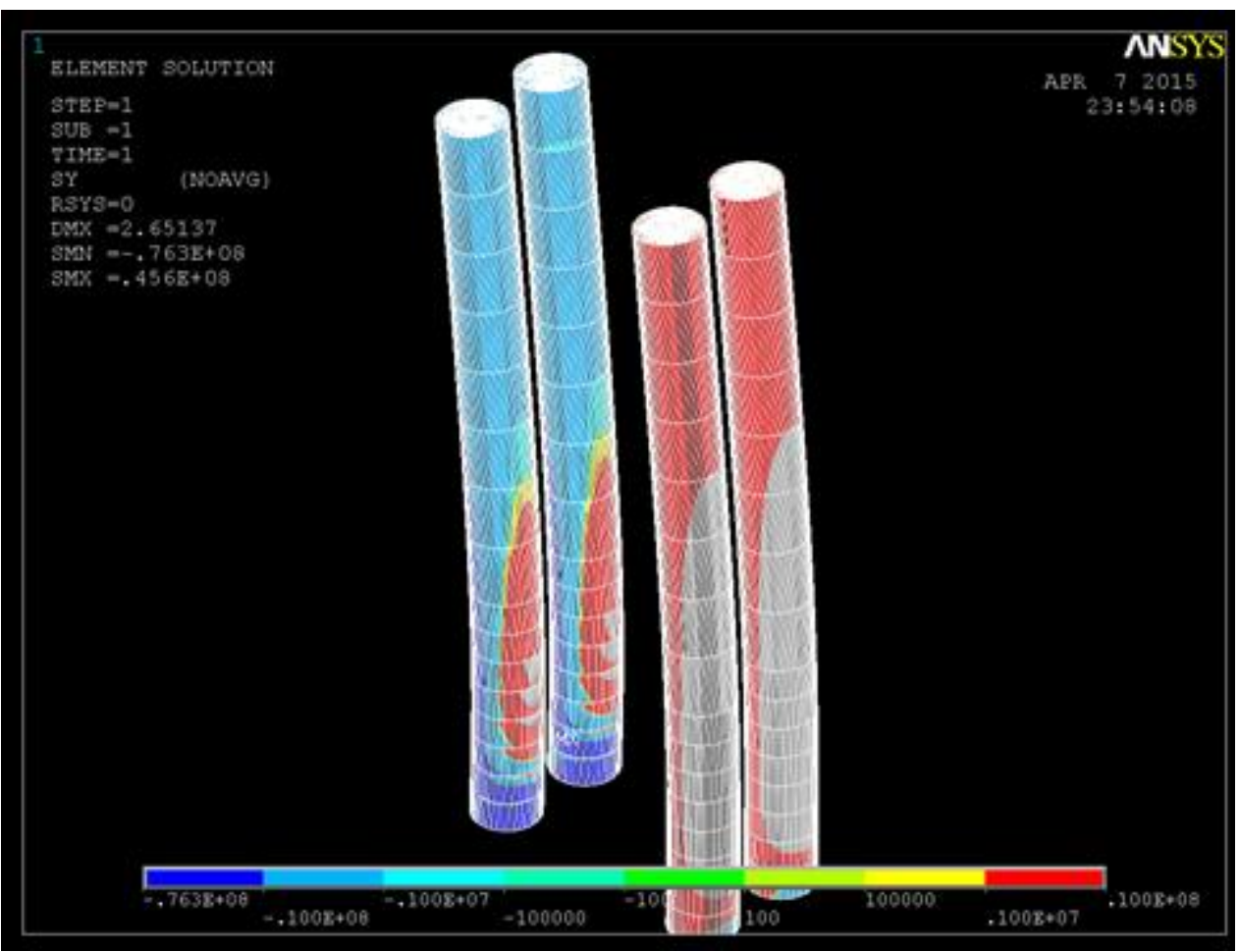

Fig. 3. Contour plots of vertical stresses in steel rebars.

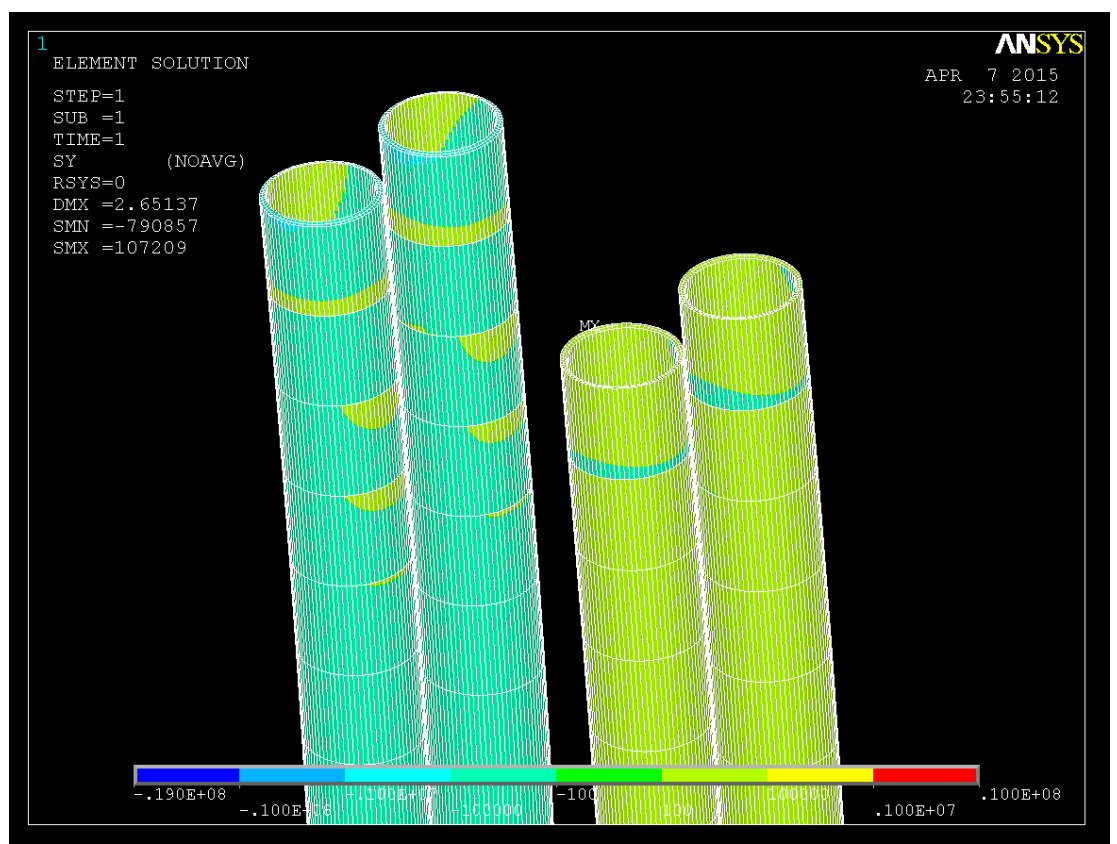

Fig. 4. Force distribution in epoxy resin layer. 


\section{Conclusion}

The analysis of complex material behavior of a glued laminated timber beam, steel reinforcement bars and epoxy resin using ANSYS software package has shown that this software solution produces outstanding results in:

- defining strength and rigidity of glulam beams with transverse reinforcement;

- calculating stress distribution over beam cross-sections;

- studying correlations between geometric properties of structures and their strength and rigidity;

- estimating the influence of anisotropic properties of wood on the stress-strain state of structures.

The analysis has confirmed experimental data and has shown that metal reinforcement in areas of increased load and near supports helps prevent deformations typical for glued laminated timber structures [3].

\section{References}

1. N.S. Blokhina, A G. Galkin, matecconf, 117, 00019 (2017)

2. N.S. Blokhina, AMML, 405-408, 2686 (2013)

3. S.B. Turkovskij, A.A Pogorel'tsev, I.P. Preobrazhenskaya, Kleenye derevyannye konstruktsii s uzlami na vkleennykh sterzhnyakh v sovremennom stroitel'stve (Moskva, RIF Strojmaterialy, 2013)

4. V.E. Krivonozhko, A.V. Lychev, F.R.Forsund, Docl. Math. 94, 3, (2016) 